\title{
Design of the Oscillating Mechanism of the Self- propelled Aerial Work Platforms
}

\author{
Xuhong $\mathrm{Gao}^{1}$, Xiangyang $\mathrm{Xu}^{1}$ and $\mathrm{Di} \mathrm{Sun}^{2, *}$ \\ ${ }^{1}$ School of Transportation Science and Engineering, Beihang University, Beijing 100191, China \\ ${ }^{2}$ Marine Engineering College, Jimei University, Xiamen 361021, China \\ ${ }^{*}$ Corresponding author
}

\begin{abstract}
The self-propelled Aerial Work Platforms (SAWP) will go through the rough road, therefore, the oscillating mechanism should be mounted on the chassis in order to adapt to safe and comfortable operation of the SAWP. When the boom of the SAWP need to be rotated by $360^{\circ}$ continuously, the stability of the SAWP should lower even the rollover might occur, therefore, the oscillating mechanism must be locked completely in some working conditions. In this paper, according to the structure characteristic of the SAWP, safety control conditions were analyzed and the oscillating mechanism was designed. The stability and reliability of the oscillating mechanism have been verified by the ground test and the customer service, and the results are satisfied.
\end{abstract}

Keywords-self-propelled aerial work platforms; oscillating mechanism; stability

\section{INTRODUCTION}

\section{A. Background}

The self-propelled Aerial Work Platforms (SAWP), also known as one of the aerial devices, are mechanical devices used to provide temporary access for people or equipments to inaccessible areas [1], which are widely used in Aerospace, Aviation, Shipbuilding, Petroleum, Construction and other industries. The SAWP can drive themselves around a site. In some instances, the SAWP will be able to move whilst the job is in progress, although this is not possible on units that require secure outriggers. The power can be almost any form of standard mechanical drive system, including diesel or electric or hybrid powered.

The SAWP were researched early in 1960s in the United States and the Europe. Since 1980s, Japan and Korea started to work on the units. After 2000s, China also began to focus on the SAWP. Until now, the famous brands are JLG, Genie, Haulotte, Niftylift, Aichi, Junjin, etc [2]. At the same time, the burgeoning brands in China are Lansel, Sinoboom, DL, etc.

It seems that these products are alike, however their technical details are different. For example, in order to balance riding comfort and operating stability of the SAWP, telescopic bridges and hydraulic floating cylinders were used to the units [3]. In this paper, one oscillating mechanism was designed and analyzed and the test results were discussed.

When the SAWP were designed, the oscillating mechanism was mounted between the front axle and the frame to balance the riding comfort and operating stability. The oscillating mechanism includes a set of trigger mechanism, two hydraulic cylinders, the hydraulic valve groups and a proximity sensor.

When the SAWP move on the rough road, the trigger mechanism should be activated, the oil-way of two hydraulic cylinders is connected, and the front axle would be swung along the longitudinal centerline of the frame. As a result, the riding comfort of the SAWP should be improved since the effect of the road roughness has been reduced.

The SAWP can be rotated by $360^{\circ}$ continuously, and the center of the SAWP mass is changing constantly when the units rotate. When the boom was rotated to the position where it is vertical to the longitudinal centerline of the frame, the stability of the SAWP should be reduced [4]. Therefore, it is necessary to adopt the oscillating mechanism in consideration of safety operation.

\section{B. Method}

The oscillating mechanism is designed based on the structure characteristic of the SAWP and safety requirements, and the details are listed as follows.

- The threshold boundary should be determined according to driving speed, slope, length and angle of the boom and rated load on the platform.

- The hydraulic valve groups and the hydraulic cylinders should be designed.

- The trigger mechanism including the roller, the guide plate and the bracket should be designed, which can be assembled by using bolts and pins in order to control the hydraulic valve groups.

- When the reversing valve in the hydraulic valve groups is activated by the trigger mechanism, the compression stroke of the reversing valve should be in Min. and Max. values, so the proximity sensor must be used and the safety control circuit should be designed.

- Under severe working conditions and steep roadway, the driving test should be carried out in order to check the stability and reliability of the oscillating mechanism.

- The service information from the customers should be collected and analyzed, which is valuable and important to improve technical performances of the oscillating mechanism. 


\section{DESIGN PROPOSAL}

\section{A. The Threshold Confirmation}

In the oscillating mechanism, two hydraulic cylinders are mounted between the frame and the front axle pinned with the frame, as shown in Figure 1.

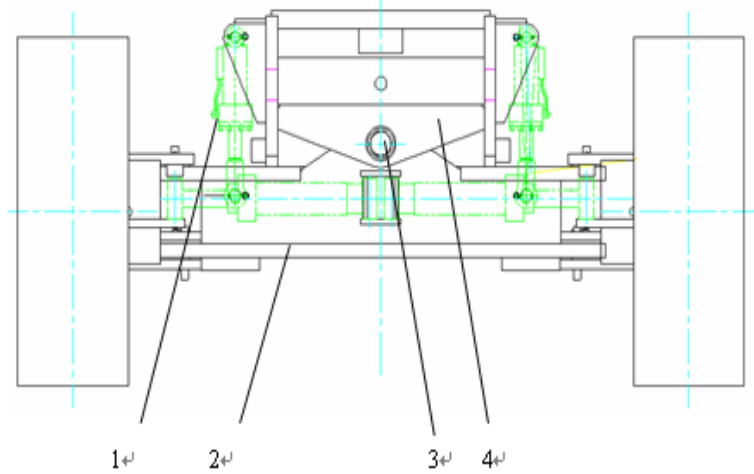

1. Hydraulic cylinder 2. Front axle 3. Main pin 4.Frame

\section{FIGURE I. FRONT AXLE AND HYDRAULIC CYLINDER POSITION}

The proper gap should be reserved between the vertical plate lower edge of the frame and th cover plate top surface of the front axle. When the SAWP move on the rough road, the intersection angle between the boom centerline and the frame centerline changes from $0^{\circ}$ to $360^{\circ}$. At the same time, the gap value changes constantly. Given the stability and reliability of the SAWP, the intersection angle should be in some range. It is obvious that the oscillating mechanism should not work unless it is in the assigned intersection angle [5].

It can be seen that the confirmation of the intersection angle is crucial. First of all, dynamical model of the SAWP should be set up and the theory algorithm should be determined. Secondly, experience method from the service information should be considered. Last but not least, the intersection angle should be designed on the basis of EN 280:2010. Based on the above analysis, the best intersection angle is determined between $\left[-30^{\circ},+30^{\circ}\right]$.

\section{B. Hydraulic System Design}

The Hydraulic system should be designed to adapt to practical requirements. On the one hand, the reversing valve in the hydraulic valve groups can work when the boom centerline is in $\left[-30^{\circ},+30^{\circ}\right]$, at the same time, the oil-way of two hydraulic cylinders is connected. On the other hand, the reversing valve in the hydraulic valve groups can be sprung when it is out of this range [6]. Certainly, the oil-way of two hydraulic cylinders is cut off. Therefore, two-way hydraulic balance valves should be adopted in the hydraulic system, as shown in Figure 2.

When the SAWP move on the rough road, the reversing valve (shown as No.3 in Figure 2) is activated, and the twoway hydraulic balance valves (shown as No.2 in Figure 2) will be opened. At the same time, hydraulic oil would flow into two hydraulic cylinders, as a result that one cylinder is in extension stroke and another cylinder is in compression stroke (shown as No.1 in Figure 2), which allow the front axle to swing around the main pin of the frame.

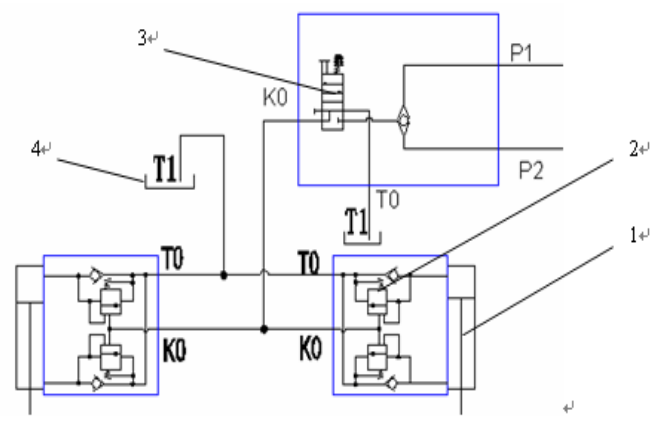

1. Hydraulic cylinder 2. Two-way hydrad lic balance valve 3 . Reversing valve 4. Tank

\section{FIGURE II. HYDRAULIC SYSTEM SCHEMATIC DIAGRAM}

When the SAWP move on the smooth road, the reversing valve is sprung, therefore, the oil way is closed, and two-way hydraulic balance valves should be closed too. At this moment, hydraulic oil wouldn't flow between two hydraulic cylinders, as a result that the two hydraulic cylinders remain steady status [7], so the front axle wouldn't swing.

\section{The Trigger Mechanism Design}

The turntable can be rotated from $0^{\circ}$ to $360^{\circ}$ continuously, however, the reversing valve can only be activated in $\left[-30^{\circ}\right.$, $\left.+30^{\circ}\right]$. Therefore, the trigger mechanism is designed to activate the reversing valve as required automatically. The main structures of the trigger mechanism are as shown in Figure 3.

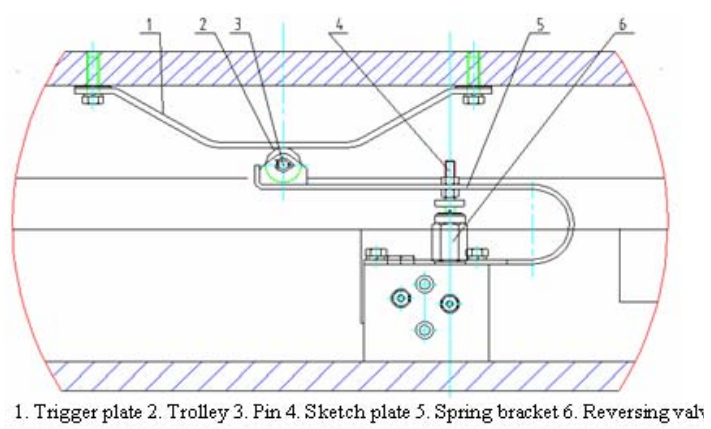

FIGURE III. THE TRIGGER MECHANISM DIAGRAM

The operations of the trigger mechanism are listed as follows. When the boom centerline is in $\left[-30,+30^{\circ}\right]$, the trigger plate (shown as No.1 in Figure 3 ) is rotated together with the turntable, at the same time, the trigger plate should contact with the trolley (shown as No.2 in Figure 3). When the trolley scroll down to the center of the trigger plate, the spring bracket (shown as No.5 in Figure 3) is compressed. The sketch plate (shown as No.4 in Figure 3) would move to the spool end of the reversing valve (shown as No.6 in Figure 3) as the compressed deformation increasing gradually. Then the 
reversing valve would be opened, the oil-way of two hydraulic cylinders would be connected, and the front axle would swing.

On the contrary, when the boom centerline is out of $\left[-30^{\circ}\right.$, $\left.+30^{\circ}\right]$, the trigger plate would not touch with the trolley. Then the spring bracket would reset and the reversing valve is cut off. In this case, the front axle also would not swing.

\section{The Circuit System Design}

Whether the front axle would swing or not controlled by the trigger mechanism and the valve groups, the accuracy and reliability of the oscillating mechanism are guaranteed by the spring bracket.

In fact, the working status of the spring bracket should be monitored at anytime, since the oscillating mechanism would be affected even failure in case of damage appearing. Therefore, the safety warning circuit system should be designed [8]. The circuit system includes the proximity sensor and one controller, as shown in Figure 4.

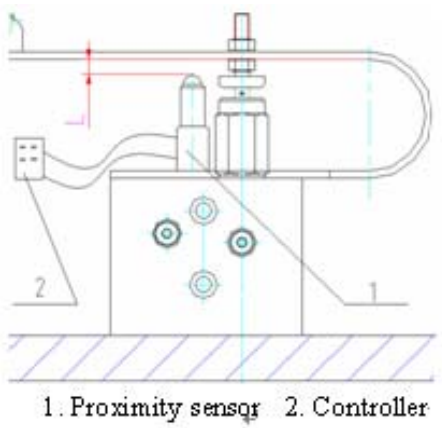

FIGURE IV. PROXIMITY SENSOR ASSEMBLY DIAGRAM

When the spring bracket is compressed, the gap value marked "L" between the proximity sensor and the spring bracket is set as the standard value. Once the standard value exceeds the upper or lower limit, the examination signal will be transmitted to the controller by the software module [9]. Then the instructions of the boom up/down or extend/retract and turntable rotate would be issued to the main valves, and then the actions would be restricted [10]. At the same time, the operator would be alarmed to stop working and check the units until the troubleshooting [11].

The logic control diagram is as shown in Figure 5. Pictures of the oscillating mechanism mounted on the SAWP are as shown in Figure 6, Figure 7 and Figure 8.

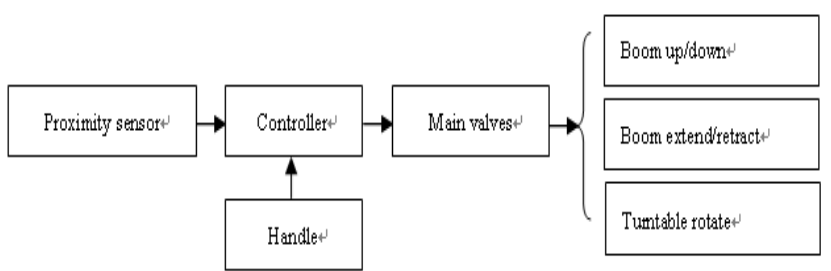

FIGURE V. LOGIC CONTROL DIAGRAM

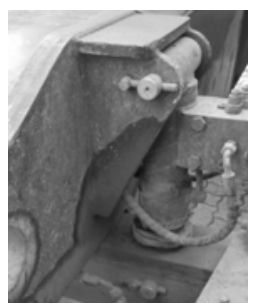

FIGURE VI. HYDRAULIC CYLINDER AND BALANCE VALVE

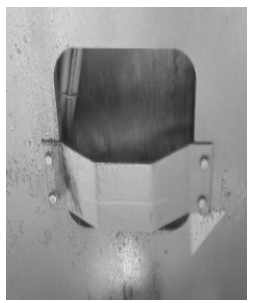

FIGURE VII. TRIGGER PLATE

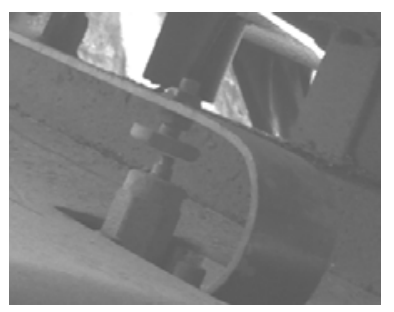

FIGURE VIII. SPRING BRACKET AND HYDRAULIC VALVE GROUPS

\section{TESTS}

\section{A. Ground Test}

In order to test the accuracy and reliability of the oscillating mechanism, all kinds of tests have been carried out, and parts of tests are shown in Figure 9 and Figure 10.

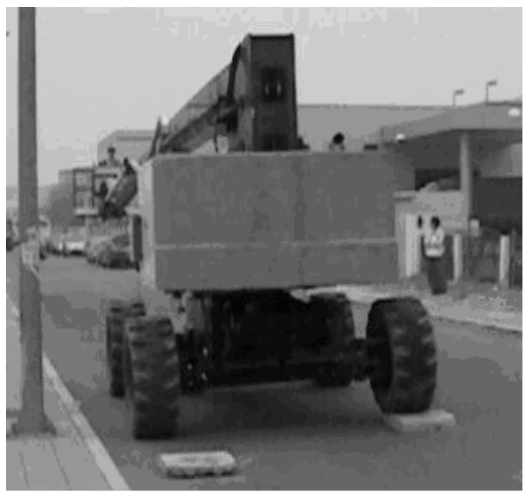

FIGURE IX. CURB TEST 


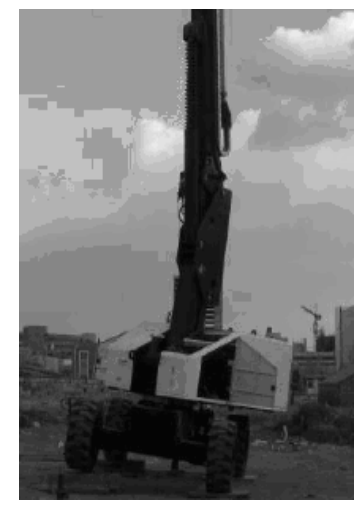

FIGURE X. SLOPE TEST
[5] T. H. Luo and W. W. Chen, "Research on stability of folding-telescopic arm for aerial work platform,” Machinery Design \& Manufacture, vol. 9 , pp.118-119, 2009.

[6] S. G. F and K. Michae, "Dynamic responses of hydraulic mobile crane with consideration of the drive system," Mechanism and Machine Theory, Vol. 38, pp.1489-1508, 2003.

[7] J. Y. Zhao, D. L. An, F. Cheng and W. Y. Ao, "Research on Hydraulic Control system for JHP26 Aerial Work Platform,” Machine Tool \& Hydraulics, vol. 38(13), pp.99-102, 2010.

[8] J. M. Quan, G. R. Wu, X. B. Wang, C. S. Jiang and G. Q. Qi, "Design and Development of the Intelligent controller for the Aerial Platform Vehicle,” Electronic Science and technology, vol. 23(1), pp.88-90, 2010.

[9] J. Y. Zhou, X. J. Meng and P. X. Ji, "Design on control system of aerial working platform, ” Construction Machinery, vol. 9, pp.65-69, 2014.

[10] J. Mirsi, Service Manual, Washington, Genie industries, inc, 2007.

[11] Dford, Service and Maintenance Manual, Houston, JLG industries, inc, 2009

The oscillating mechanism shows stability and reliability in the process of the tests and can be equipped with different types of the SWAP.

\section{B. Customer Service}

The SAWP equipped with the oscillating mechanism were continuously tracked about 5 years after sale and the results show that the oscillating mechanism is always working well.

\section{CONCLUSIONS}

With the analysis of the oscillating mechanism above, the main conclusions can be drawn as follows.

a) The key components of the oscillating mechanism are the spring bracket, the reversing valve and the proximity sensor, and the oscillating mechanism shows stability and reliability when it is in good working conditions.

b) According to the tests and the customer service, the SAWP equipped with the oscillating mechanism show the good performance in the aspect of riding comfort.

c) The oscillating mechanism is suitable to be adopted in different types of the SAWP for its perfect performance such as low-cost and easy maintenance.

\section{ACKNOWLEDGMENT}

This research was funded by Aerospace New Long March Electric Vehicle Technology Co., Ltd. and Fujian Province Education Bureau Foundation (JA15285).

\section{REFERENCES}

[1] EN 280:2010 "Mobile elevating work platforms-Design calculationsStability criteria-Construction-Safety-Examinations and tests”.

[2] F. Wang, "Aerial work platform summary of domestic and international market development," Construction Mechanization, vol. 30(12), pp.3436, 2009.

[3] D. J. Gu, R. M. Teng, S. D. Gao, R. Bai and K. Q. Gao, “Analysis of the oscillating mechanism of an Aerial work platform based on ADAMS Hydraulic-mechanical coupling simulation,” International Journal of Plant Engineering Management, vol. 13(3), pp.154-158, 2008.

[4] X. W. Zhang and L. Cai, "Safety control of aerial working platform," Construction Mechanization, vol. 30(12), pp.37-40, 2009. 